\title{
The Possible Roles of Hyperlipidemia and Mononuclear Cells in Glomeruli in Puromycin Aminonucleoside Nephrosis in Rats
}

\author{
Tomohisa Hattori, Tadashi Nagamatsu, Mikio Ito and Yoshio Suzuki \\ Department of Pharmacology, Faculty of Pharmacy, Meijo University, 150 Yagotoyama, Nagoya 468, Japan \\ Received May 20, 1995 Accepted October 16, 1995
}

\begin{abstract}
The possibility that hyperlipidemia and an increase of mononuclear cells in the glomeruli could participate in the pathogenesis of minimal change glomerulopathy was evaluated in puromycin aminonucleoside (PAN) nephrosis in rats. Significant increases in intraglomerular CD4-, IL-2-receptor (R)and ED-1-positive cells were found in PAN rats. Urinary protein excretion and mononuclear cells in the glomeruli of $1 \%$ cholesterol diet-fed rats significantly increased, compared with standard diet feeding. Moreover, administration of a subnephrogenic dose of PAN in cholesterol diet-fed rats substantially increased urinary protein excretion and mononuclear cells in the glomeruli. Additionally, antihyperlipidemia agents and immunosuppressive agents prevented urinary protein excretion and increases of CD4-, IL-2Rand ED-1-positive cells in the glomeruli of PAN nephrotic rats. Monoclonal antibodies directed against these cells also prevented urinary protein excretion. These results suggest that CD4-, IL-2R- and ED-1positive cells and hyperlipidemia are involved in the progression, but not the pathogenesis, of PAN.
\end{abstract}

Keywords: Nephrosis, Puromycin aminonucleoside, Hyperlipidemia, Cellular immunity

The nephrotic syndrome, characterized by severe proteinuria hypoproteinemia, edema formation and hyperlipidemia is a consequence of altered permselectivity of the glomerular filtration barrier. The administration of puromycin aminonucleoside (PAN) to rats results in massive proteinuria due to well-defined glomerular lesions which are similar in many aspects to human minimal change nephropathy (1). It has been widely accepted that nonimmune mechanisms such as reactive oxygen species may be important in the pathogenesis of this experimental nephrosis $(2,3)$. However, recent reports indicated that bone marrow-derived cell depletion by $\mathrm{X}$-ray irradiation or essential fatty acid deficiency improved renal function and glomerular injury of PAN nephrosis $(4,5)$. In addition, it has been reported that the supernatant of concanavalin A-stimulated peripheral mononuclear cells from human minimal change nephrotic syndrome was capable of inducting proteinuria in rats (6). Accordingly, contribution of cellular immunity abnormalities in this model has been suggested.

On the other hand, a number of investigations have suggested that alterations in lipid metabolism may be important in the pathogenesis of progressive renal injury in human and experimental glomerulonephropathy (7-9). Diet-induced hypercholesterolemia has been shown to cause renal injury in rats (10), rabbits (11) and guinea pigs (12). Moreover, increases in the numbers of monocytes and macrophages in the glomeruli of rats with hypercholesterolemia have been observed $(7,8)$. Moreover, it has also been reported that excess cholesterol amplifies several macrophage functions including phagocytosis, adhesion to endothelium and secretion of chemotactic and mitogenic substances $(13,14)$.

Here, we investigated whether mononuclear cells in the glomeruli are associated with the progression of glomerular injury in PAN nephrosis. In the first experiment, we monitored changes in the numbers of leukocyte-subsets during the course of PAN nephrosis. In the second experiment, the effects of antihyperlipidemia agents and immunosuppressive agents on urinary protein excretion in PAN nephrosis were evaluated. In addition, we investigated which mononuclear cell is associated with the progression of PAN nephrosis. In the third experiment, effects of W3/25, OX-39 and ED-1 monoclonal antibodies directed against the surface antigens of CD4 (Helper/Helper inducer T cell), IL-2-receptor (R) and monocytes/macrophages on the proteinuria in rats with PAN nephrosis were also investigated. 


\section{MATERIALS AND METHODS}

\section{Animals}

Male Sprague-Dawley strain rats, weighing approx. 200 $g$ (Nihon SLC, Hamamatsu), were used for all experiments. They were housed in groups of four to five under a 12-hr light-dark cycle with food and water freely available.

\section{Drugs}

Cholestyramine (Bristol-Myers Squibb Co., Ltd., Tokyo), simfibrate (Maruko Chemical Co., Ltd., Nagoya), cyclosporin A (Sandoz, Tokyo) and azathioprine (Sigma Chemical Co., St. Louis, MO, USA) were used. Cholestyramine and simfibrate were suspended in distilled water. Cyclosporin A was dissolved in olive oil with $1 \%$ ethanol. Azathioprine was suspended in 1\% gum arabic. Puromycin aminonucleoside (PAN) was purchased from Sigma Chemical Co.

\section{Experimental protocol}

To determine the time course of the number of leukocyte-subsets in the glomeruli after the administration of PAN, 20 animals $(\mathrm{N}=5)$ were given $10 \mathrm{mg} / 100 \mathrm{~g} \mathrm{BW}$ of PAN by intraperitoneal injection. The numbers of leukocyte subsets were determined for the kidneys on the 1st, 4th, 8th and 11th day after the administration of PAN. Tissues for immunoenzymatic staining were frozen in liquid nitrogen as described below.

To investigate the effect of hyperlipidemia on the number of leukocyte-subsets in the glomeruli of PAN nephrosis, age-matched animals were fed either a standard rat chow or a $1 \%$ cholesterol-supplemented diet (Chubu Science Materials, Nagoya). The animals were maintained on the diet for at least 2 weeks before use in the experiment. The rats were given $5 \mathrm{mg} / 100 \mathrm{~g} \mathrm{BW}$ of PAN as a subnephrogenic dose. The urinary protein excretion and the number of leukocyte-subsets were determined at various time intervals.

To examine the effects of inhibiting the hyperlipidemia and the increase in the number of leukocyte-subsets in the glomeruli in this model, rats were treated with a lipidlowering agent and an immunosuppressive agent for 11 days after the administration of PAN. Cholestyramine (1,000 mg/kg/day, p.o.), simfibrate $(1,000 \mathrm{mg} / \mathrm{kg} / \mathrm{day}$, p.o.), cyclosporin A ( $20 \mathrm{mg} / \mathrm{kg} / \mathrm{day}$, p.o.) and azathioprine $(50 \mathrm{mg} / \mathrm{kg} /$ day, p.o.) were administered to 7 rats from 5 min after the administration of PAN to 11 th day. The remaining group was orally given the vehicle instead of the test drugs and served as the control. In addition, for the control, normal animals were treated according to the above schedule but given saline instead of PAN. Urine was collected over a $24-\mathrm{hr}$ period in metabolic cages on the 4th, 7 th and 11 th day after PAN injection. Blood was also collected on the 12 th day.

\section{Urine and blood parameters}

At the beginning of the urine collection, each animal orally received $8 \mathrm{ml}$ of distilled water without feeding. The collected urine was then centrifuged at 3,000 rpm for $10 \mathrm{~min}$, and the supernatant was used for protein determination. Immediately after the urine collection, $0.4 \mathrm{ml}$ of blood was drawn from the tail vein of each of the conscious animals with a disposable microsyringe and put into a tube containing $0.025 \mathrm{ml}$ of heparin $(1,000 \mathrm{U} / \mathrm{ml})$. The blood was centrifuged at 5,000 rpm to obtain plasma for the determination of cholesterol and creatinine contents.

Determination of urinary protein, plasma cholesterol, triglyceride and creatinine contents

The urinary protein excretion was determined by the method of Kingsbury et al. (15) and the results are expressed as $\mathrm{mg} / 24$-hr urine. The cholesterol and triglyceride contents were determined by cholesterol and triglyceride determination kits (Detamina TC-5 and TG-5; Kyowa Medex Co., Ltd., Tokyo). The creatinine content was determined by a creatinine determination kit (CREEN; Kainos Lab. Inc., Tokyo).

\section{Monoclonal antibodies}

Mouse monoclonal antibodies (Serotec Co., Ltd., Oxford, England) against rat leukocyte subpopulations used in this study were as follows: OX-1 (leukocyte common antigen), W3/25 (helper/helper inducer $\mathrm{T}$ cells), ED-1 (most macrophages and some dendritic cells), OX-8 (cytotoxic/suppressor T cell), OX-39 (IL-2-receptorpositive cells) and RT1.B (Ia-positive cells).

\section{Immunohistochemistry}

Tissues for immunoenzymatic staining were fixed in paraformaldehyde-lysine-periodate (16). Serial cryostat sections were adhered on microscope slides, air-dried and preincubated with 1-2\% normal horse serum in phosphate-buffered saline (PBS) for $20 \mathrm{~min}$. Sections were then incubated with mouse anti-rat monoclonal antibodies for $90 \mathrm{~min}$, washed twice in PBS, treated with $0.3 \%$ hydrogen peroxide in methanol for 40 min to block endogenous peroxidase, and incubated with biotinated affinity purified anti-mouse IgG and avidinated horseradish peroxidase with diaminobenzidine tetrahydrochloride. The above procedures were carried out by Vecta stain ABC kit (Vector Laboratories, Inc., Burlingame, CA, USA). All steps were performed at room temperature. 
Quantification of leukocytes on tissue sections

Labelled cells within each glomerulus were counted by an image analyzer (Toyobo V1; Toyobo Co., Ltd., Tokyo) and the results are expressed as the number of cells per glomerular cross section (17). Cell counts were performed three times to reduce counting errors.

Effects of CD4-, IL-2R-and ED-1-positive cells depletion on PAN nephrosis

W3/25, OX-39 and ED-1 monoclonal antibodies against CD4 antigen, IL-2R and ED-1 antigen, respectively, were used to deplete these cells. These antibodies were diluted tenfold with PBS, and $0.5 \mathrm{ml}$ of diluted monoclonal antibody ( $0.48 \mathrm{mg}$ of immunoglobulin fraction) was daily administered to the rats with PAN nephrosis by intravenous injection from the day after the PAN injection to the 11th day. The nephrotic control animals and normal control were injected with $0.48 \mathrm{mg}$ of normal mouse immunoglobulin.

This amount of monoclonal antibodies was capable of reducing the number of each type of cell in the glomeruli by approx. $80 \%$, when these antibodies were injected in-

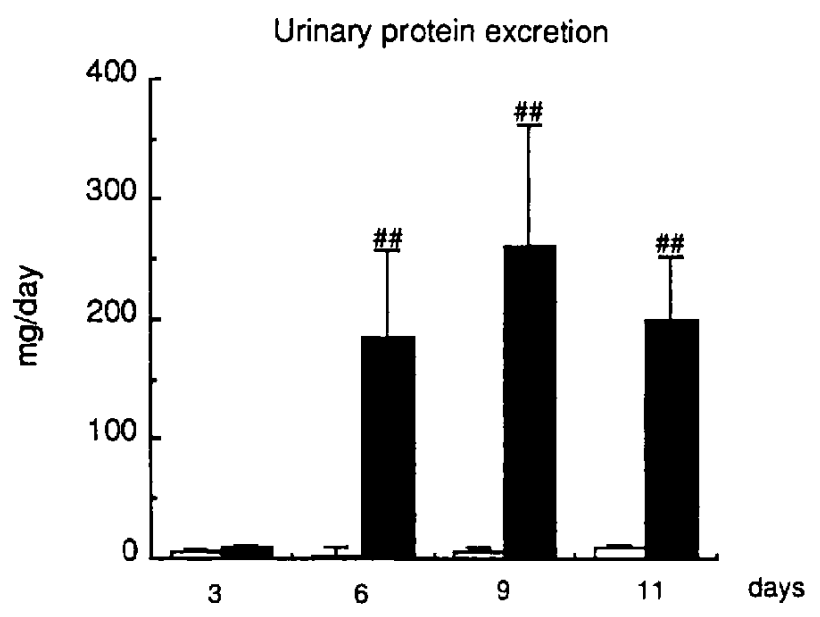

Fig. 1. The changes in proteinuria, cholesterol and triglyceride contents during the course of puromycin aminonucleoside nephrosis in rats. Each column represents the mean \pm S.D. of 5 rats. a significant difference from the normal at $\mathrm{P}<0.01 . \square$ : Normal, 口: Nephrosis. travenously in the rats with crescentic nephritis on the 15 th day at once (18).

\section{Statistical analyses}

The data represent means $\pm S$.D. and the results were statistically evaluated by one way analysis of valance with Student's $t$-test. Inhibitory percentage was calculated as follows:

$$
\begin{aligned}
& \text { Inhibitory percentage }(\%) \\
& \quad=(\text { Control-Test drugs }) \times 100 /(\text { Control-Normal })
\end{aligned}
$$

\section{RESULTS}

Time course of the changes in the number of leukocyte subsets in glomeruli of rats with PAN nephrosis

Urinary protein excretion, plasma cholesterol and triglyceride (Fig. 1): The urinary protein excretion in the PAN nephrosis significantly increased from the 6th day to the 11 th day after PAN injection. Plasma cholesterol and triglyceride contents in the PAN nephrotic group were also elevated from the 9th day.

Total leukocyte (leukocytes common antigen) and total
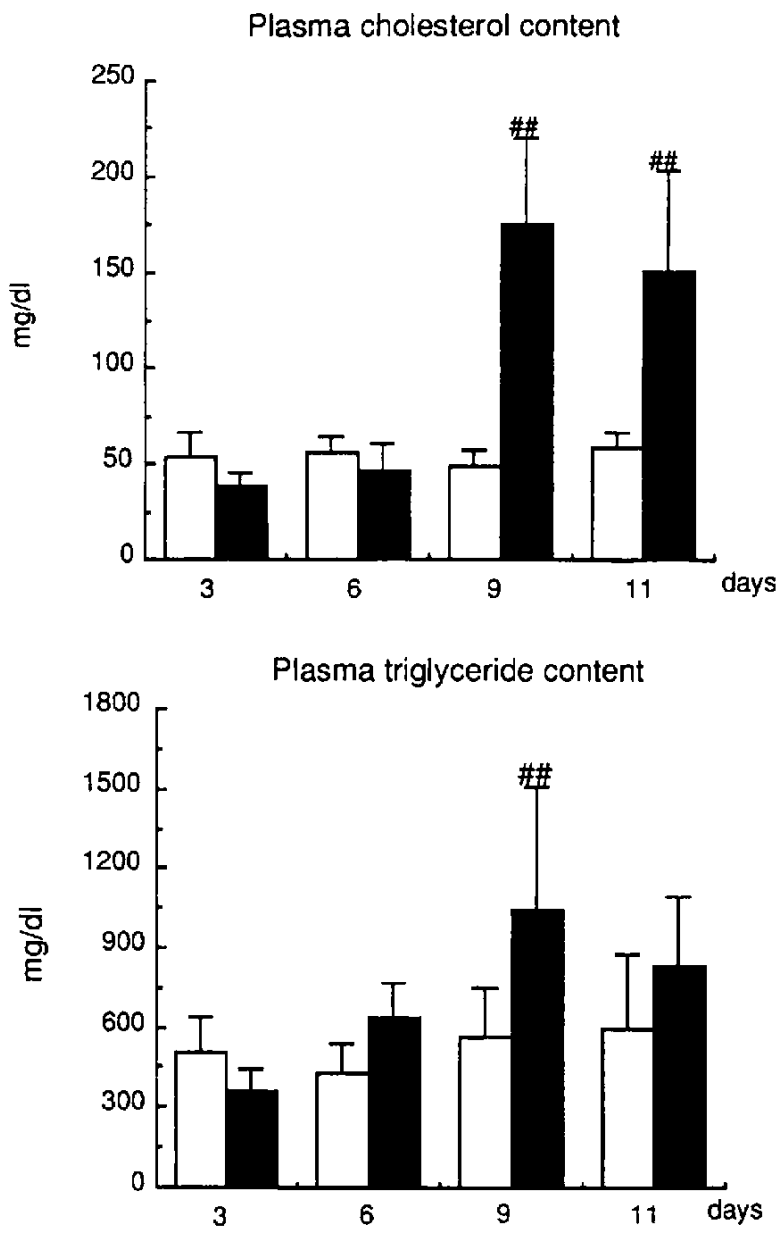


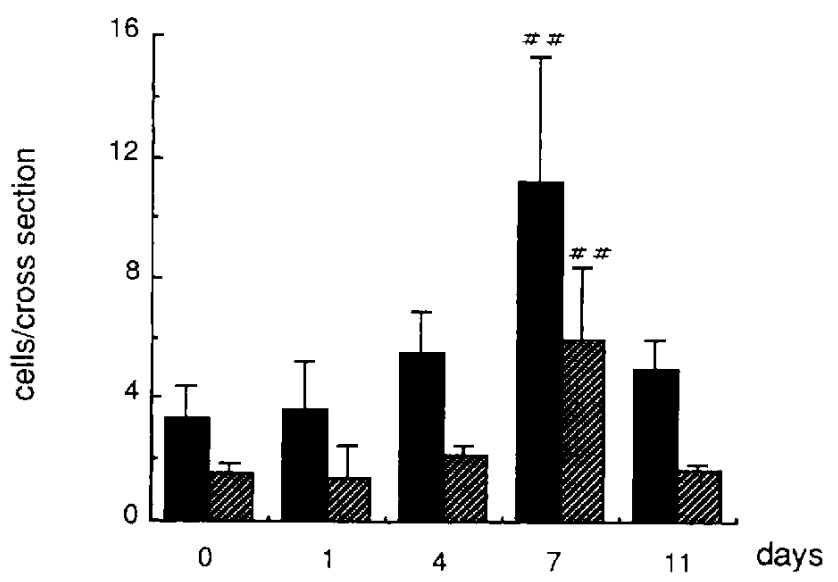

Fig. 2. The changes in the number of total leukocytes and total $T$ lymphocytes (CD-3) during the course of puromycin aminonucleoside nephrosis in rats. Each column represents the mean \pm S.D. of 5 rats. ${ }^{\#}$ shows a significant difference from the day matched normal at $\mathrm{P}<0.01$. The number of cells on day 0 denotes the mean of normal rats throughout the various time intervals. $\square$ : Total leukocytes (leukocyte common antigen), Total lymphocytes (CD-3).

lymphocyte (CD3) (Fig. 2): A significant increase in the number of total leukocytes labelled by OX-1 and total lymphocytes labelled by OX-19 on the 7th day were seen in the glomeruli of rats with PAN nephrosis $(\mathrm{P}<0.01)$.

Helper/Helper inducer $T$ cell (CD4)-, cytotoxic/suppressor $T$ cell (CD8)- and IL-2R-positive cells (Fig. $3 A$ ): The number of $\mathrm{CD} 4$, as labelled by $W 3 / 25$, in the glomeruli showed a significant increase on the 7th day. The number of IL-2R-positive cells, as labelled by IL-2R monoclonal antibody, also increased from the 4th day to the 11th day. The number of IL-2R-positive cells was maximal at the 7 th day. In contrast, there was no significant increase in the number of CD8-positive cells, as labelled by $\mathrm{OX}-8$ monoclonal antibody, during the experimental periods.

Macrophages/monocytes and Ia-positive cells (Fig. 3B): Macrophages/monocytes numbers, as labelled by ED-1 monoclonal antibody, in the glomeruli of PAN nephrotic rats were significantly increased on the 7 th day and 11 th day. However, the number of Ia-positive cells labelled by RT1.B monoclonal antibody in the glomeruli of PAN nephrotic rats did not alter during the experimental period.

Effect of $1 \%$ cholesterol diet on subnephrogenic dose of PAN (Figs. 4 and 5): Urinary protein excretion in $1 \%$ cholesterol diet rats was significantly higher than that of standard diet rats, throughout the experimental period. By the 7th day after the administration of a subnephrogenic dose of PAN, the $1 \%$ cholesterol diet rats showed an increase in urinary protein excretion (Fig. 4). This increase was statistically not significant, but the great $\mathrm{F}$ ratios $(\mathrm{P}<0.01)$ show that the $1 \%$ cholesterol diet potentiated the effect of PAN in one or a few animals of each group. The numbers of CD4-, IL-2R-positive cells and macrophage/monocyte in $1 \%$ cholesterol diet rats with the subnephrogenic dose of PAN were significantly higher than those in rats with only the subnephrogenic dose of PAN. These cells in the glomeruli of the $1 \%$ cholesterol diet rats also increased, compared with those of standard diet rats (Fig. 5). The cholesterol content in both the $1 \%$ cholesterol group and $1 \%$ cholesterol with the subnephrogenic dose of PAN was significantly increased,
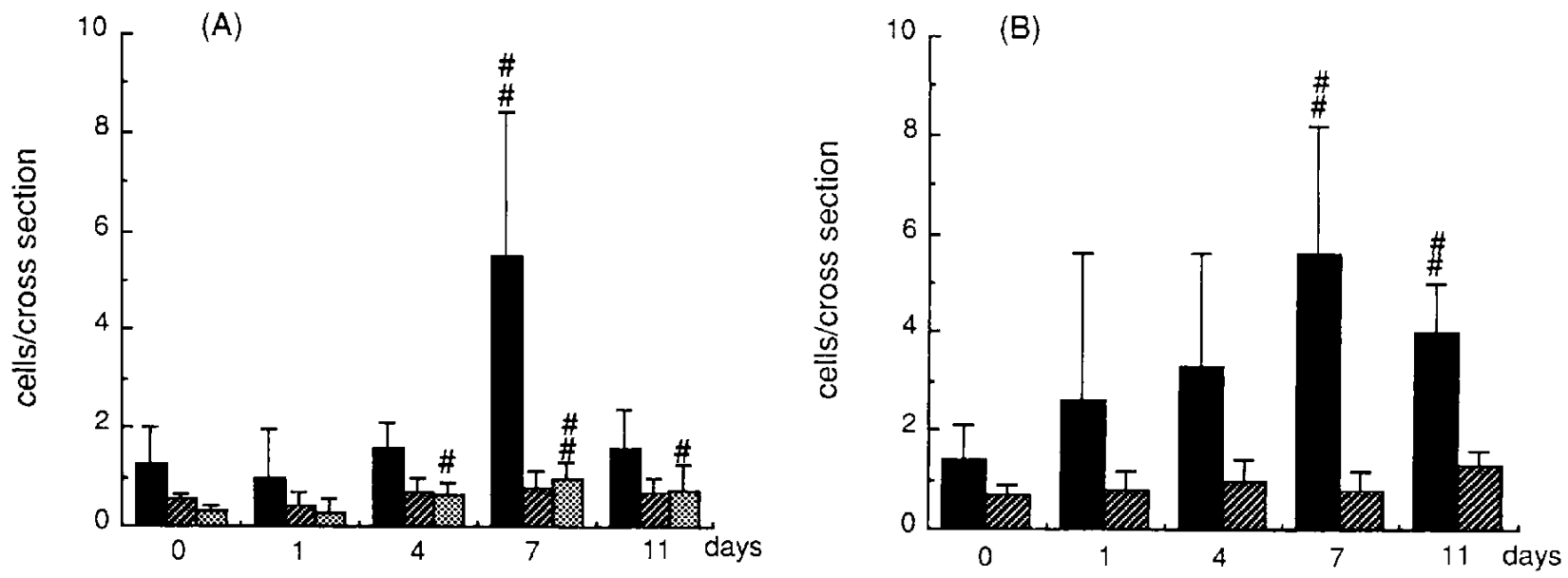

Fig. 3. The changes in the numbers of Tlymphocyte-subsets, macrophages and la-positive cells during the course of puromycin aminonucleoside nephrosis in rats. Each column represents the mean \pm S.D. of 5 rats. ${ }^{\#}$ and ${ }^{\# \text { indicate a significant }}$ difference from the day matched normal at $P<0.05$ and $P<0.01$, respectively. The number of cells on day 0 denotes the mean of normal rates throughout the various time intervals. (A) $\square$ : Helper/Helper inducer T cell $(C D 4+$ ), Cytotoxic/suppressor T cell $(\mathrm{CD8}+)$, 圆: IL-2-receptor-positive cell. (B) $\square$ : Macrophage/monocyte (ED+), Ia-positive cell. 


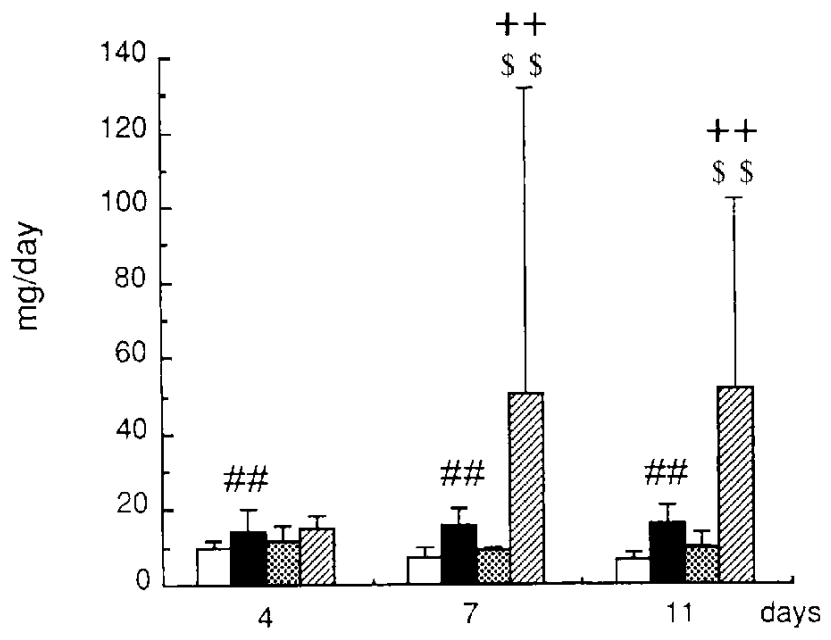

Fig. 4. Effect of 1\% cholesterol feeding or subnephritogenic dose of PAN on urinary protein excretion in rats. Each column represents the mean \pm S.D. of 5 rats. ${ }^{\text {f }}$ indicates a significant difference from the standard diet group at $\mathrm{P}<0.01 .^{++}$and ${ }^{\$ \$}$ indicate that the F-ratio vs standard diet group and the F-ratio vs PAN-treated standard diet group, respectively, were $\mathrm{P}<0.01$. $\square$ : Standard diet, $\square$ : $1 \%$ cholesterol diet, W: Subdose of PAN + Standard diet, 四: Subdose of PAN $+1 \%$ cholesterol diet.

compared with each control (data not shown).

Effects of cholestyramine, simfibrate, azathioprine and cyclosporine A on proteinuria (Figs. 6 and 7)

Cholestyramine at $1,000 \mathrm{mg} / \mathrm{kg} /$ day, p.o. prevented the urinary protein excretion by the 7 th day. Simfibrate at $1,000 \mathrm{mg} / \mathrm{kg} /$ day, p.o. also prevented the urinary protein excretion by the 11 th day. Cyclosporin $A$ at $20 \mathrm{mg}$ $/ \mathrm{kg} /$ day, p.o. prevented the urinary protein excretion by the 4th day. Azathioprine $(50 \mathrm{mg} / \mathrm{kg} /$ day $)$ treatment in- hibited excretion by the 7th day.

Effects of cholestyramine, simfibrate, azathioprine and cyclosporin $A$ on the number of CD4-, IL-2R-positive cells and macrophage/monocyte in PAN nephrosis (Table 1): On the 11th day, the number of CD4- and IL-2Rpositive cells and macrophage/monocyte in the glomeruli of PAN nephrosis were significantly increased, compared with normal rats. Azathioprine completely prevented the increase in the number of these cells in the glomeruli. Cholestyramine inhibited the increases in the numbers of IL-2R-positive cells and macrophages. Simfibrate and cyclosporin A inhibited the increases in CD4- and IL-2Rpositive cells in the glomeruli.

Effects of monoclonal antibodies against ED-1, $I L-2 R$ and $C D 4$ on urinary protein excretion in $P A N$ nephrosis in rats (Fig. 8)

The urinary protein excretion of nephrotic control was markedly increased by the 7 th day. In contrast, the administration of ED-1 monoclonal antibody resulted in a marked attenuation of increased proteinuria. In addition, the antinephrotic effect of monoclonal antibody against IL-2 receptors was stronger than that of ED-1 monoclonal antibody.

\section{DISCUSSION}

Minimal change nephrotic syndrome (MCNS) is a form of glomerular disease of unknown etiology, characterized by normal glomerular histologic characteristics, epithelial cell swelling and foot process fusion on electron microscopic examination and severe proteinuria. However, recent investigations have provided evidence indicating that MCNS may be related to a T-cell disorder $(19,20)$.
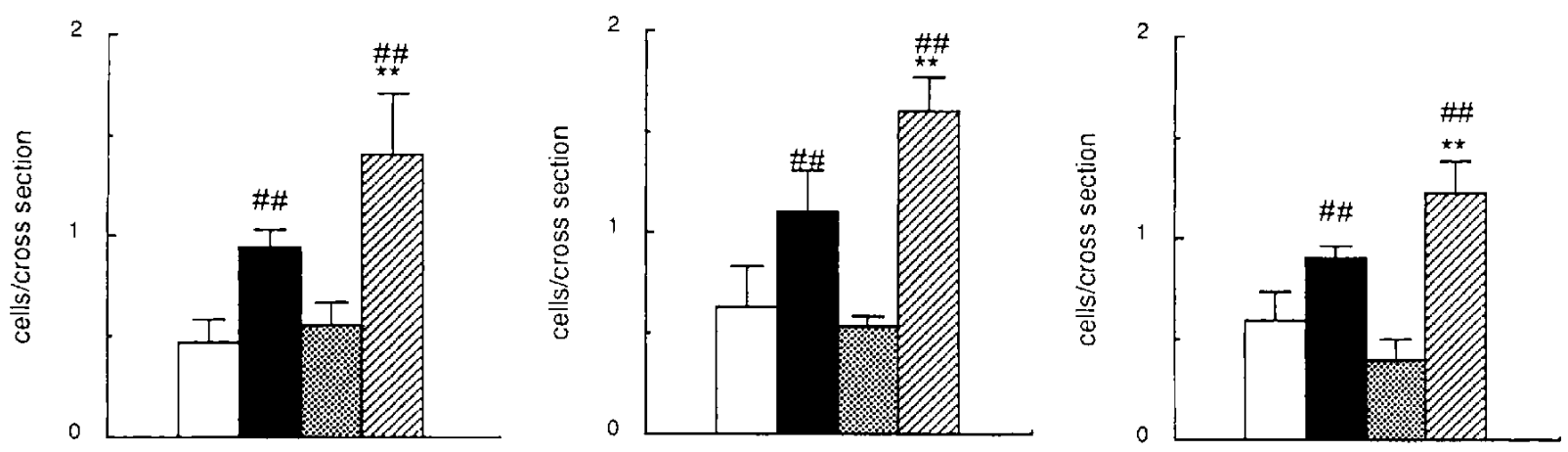

Fig. 5. Effects of $1 \%$ cholesterol feeding or subnephritogenic dose of PAN on CD4 + , IL-2-receptor + and ED-1 + cells in PAN nephrosis in rats. Each column represents the mean \pm S.D. of 8 rats. ${ }^{* \prime \prime}$ indicates a significant difference from the standard diet group at $\mathrm{P}<0.01$. ${ }^{* *}$ shows a significant difference from the PAN-treated standard diet group at $\mathrm{P}<0.01$. $\square$ : Standard diet, 口: $1 \%$ cholesterol diet, $1 . \mathrm{l}$ : Subdose of PAN + Standard diet, 
Urinary protein excretion

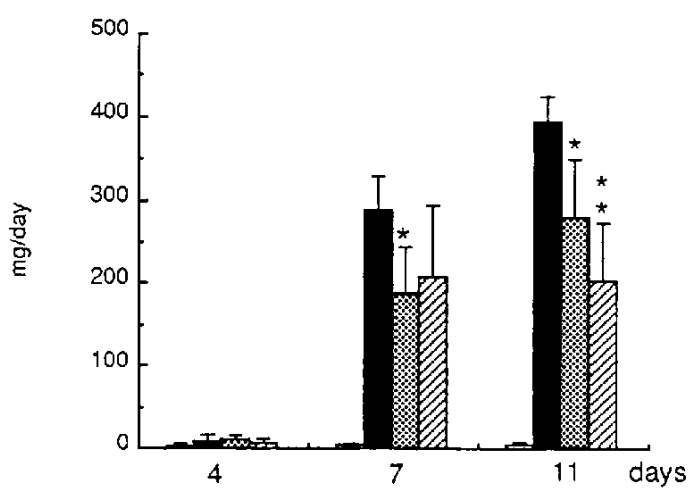

Plasma cholesterol content

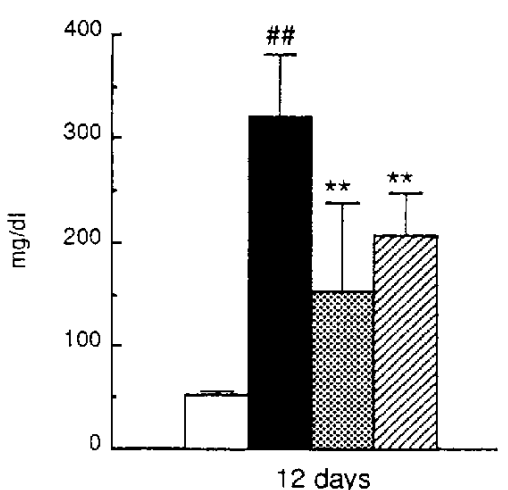

Plasma triglyceride content

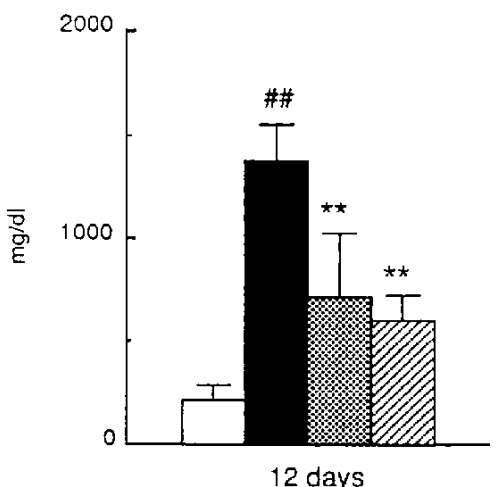

Fig. 6. Effects of cholesteramine and simfibrate on urinary protein excretion, plasma cholesterol and triglyceride contents in puromycin aminonucleoside nephrosis in rats. Each column represents the mean \pm S.D. of 7 rats. $"$ indicates a significant difference from the control at $\mathrm{P}<0.01$. $^{*}$ and ${ }^{* *}$ show a significant difference from the control at $\mathrm{P}<0.05$ and $\mathrm{P}<0.01$, respectively. $\square$ : Normal; $\square$ : Control; $:$ : Cholestyramine, $1000 \mathrm{mg} / \mathrm{kg} / \mathrm{day}$; $\because$ : Simfibrate, $1000 \mathrm{mg} / \mathrm{kg} / \mathrm{day}$.
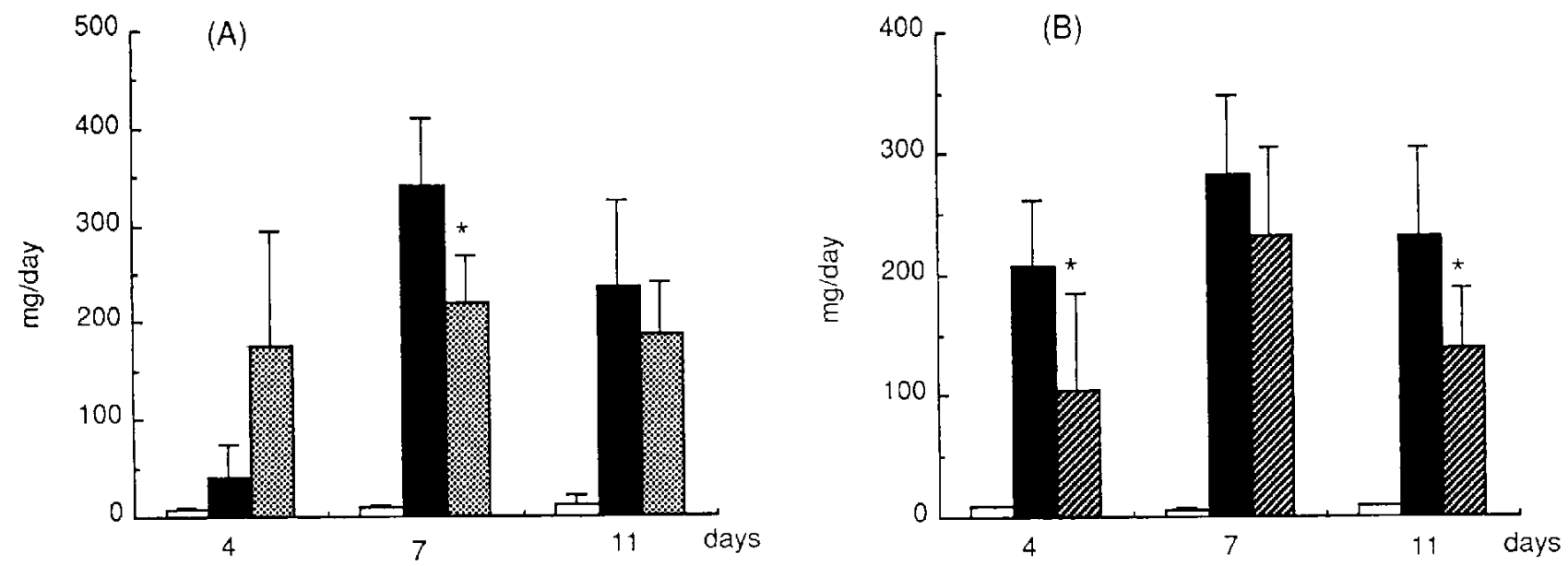

Fig. 7. Effects of azathioprine and cyclosporin $A$ on urinary protein excretion in puromycin aminonucleoside nephrosis in rats. Each column represents the mean \pm S.D. of 8 rats. ${ }^{*}$ indicates a significant difference from the control at $P<0.05$. (A) $\square$ :

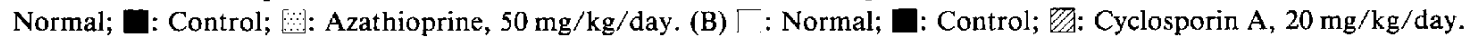

Tahle 1. Effects of cholestyramine, simfibrate, azathioprine and cyclosporin A on the number of CD4+, IL-2receptor + and ED-1 + cells in the glomeruli of puromycin aminonucleoside nephrotic rats

\begin{tabular}{|c|c|c|c|c|c|}
\hline Groups & & $\mathbf{n}$ & CD4 + cells & $\begin{array}{l}\text { IL-2-receptor }+ \text { cells } \\
\text { (cells/cross section) }\end{array}$ & ED-1+ cells \\
\hline Normal & & 5 & $0.40 \pm 0.35$ & $0.42 \pm 0.25$ & $0.24 \pm 0.21$ \\
\hline Control & & 7 & $1.27 \pm 0.31^{\# \#}$ & $1.60 \pm 0.44^{44}$ & $1.26 \pm 1.03^{4}$ \\
\hline Cholestyramine & $1,000 \mathrm{mg} / \mathrm{kg} /$ day & 7 & $0.94 \pm 0.30$ & $0.58 \pm 0.22^{* *}$ & $0.38 \pm 0.26^{*}$ \\
\hline Simfibrate & $1,000 \mathrm{mg} / \mathrm{kg} /$ day & 7 & $0.85 \pm 0.17^{*}$ & $0.73 \pm 0.30^{* *}$ & $0.58 \pm 0.25$ \\
\hline Normal & & 5 & $0.24 \pm 0.28$ & $0.25 \pm 0.06$ & $0.48 \pm 0.19$ \\
\hline Control & & 8 & $0.85 \pm 0.30^{*}$ & $0.80 \pm 0.26^{1.4}$ & $0.90 \pm 0.21^{4}$ \\
\hline Azathioprine & $50 \mathrm{mg} / \mathrm{kg} /$ day & 8 & $0.64 \pm 0.30$ & $0.42 \pm 0.15^{* *}$ & $0.92 \pm 0.17$ \\
\hline Cyclosporin A & $20 \mathrm{mg} / \mathrm{kg} / \mathrm{day}$ & 8 & $0.28 \pm 0.23^{* *}$ & $0.28 \pm 0.08^{* *}$ & $0.68 \pm 0.18$ \\
\hline
\end{tabular}

The measurements of the number of immunoreactive cells were done on the 11 th day after the initial day of puromycin amino-nucloside treatment. Values indicate means \pm S.D. and $n$ indicates the number of rats. "and * show a significant difference from the normal at $\mathrm{P}<0.05$ and $\mathrm{P}<0.01$, respectively. ${ }^{*}$ and ${ }^{* *}$ show a significant difference from the control at $\mathrm{P}<0.05$ and $\mathrm{P}<0.01$, respectively. 

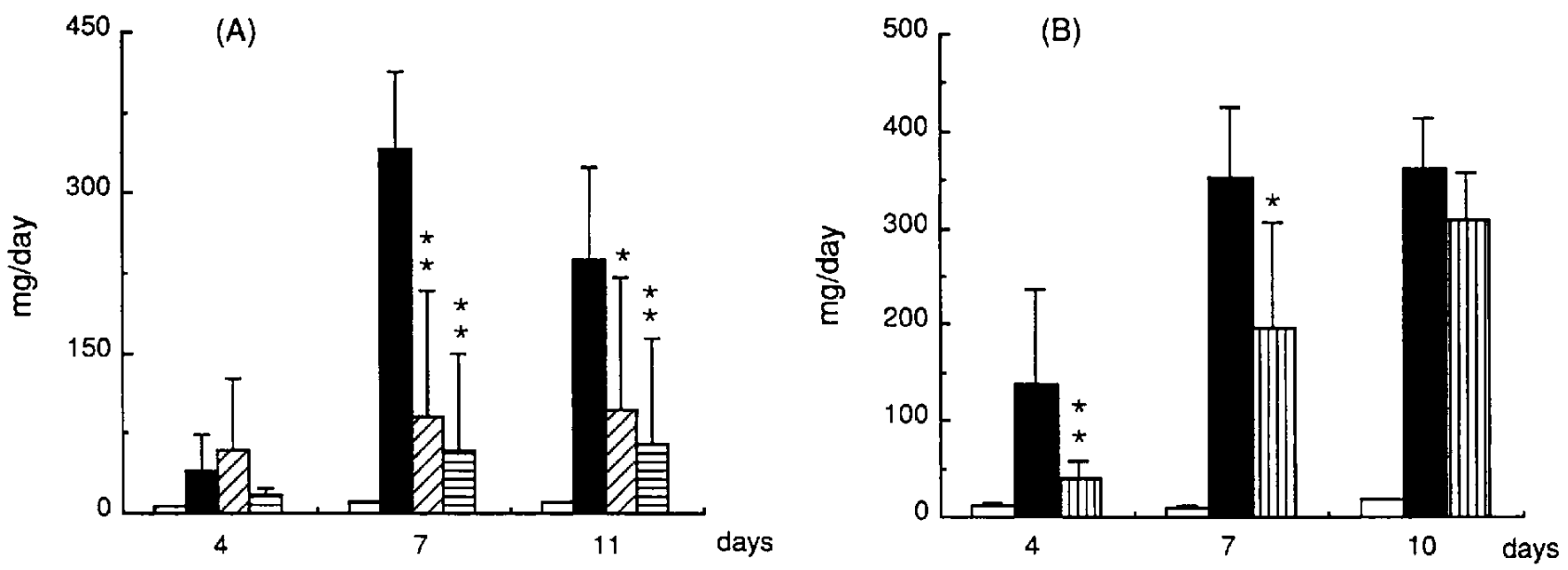

Fig. 8. Effects of monoclonal antibodies against ED-1, IL-2R and CD4 on urinary protein excretion in puromycin aminonucleoside nephrosis in rats. Each column represents the mean \pm S.D. of 5 rats. * and ** indicate a significant difference from the control at $P<0.05$ and $P<0.01$, respectively. (A) $\square$ : Normal, $\square$ : Control, $\mathbb{Z}$ : ED-1 monoclonal antibody, $⿴ 囗 十$ : IL-2R monoclonal antibody. (B) $\square$ : Normal, $\square$ : Control, 四: CD4 monoclonal antibody.

Eyres et al. (20) demonstrated that patients with MCNS had lymphocyte-mediated cytotoxicity directed against an epithelial cell culture derived from human kidney. These results could support a possibility that abnormalities of cellular immunity may be involved in development of MNCS.

The present study demonstrated that the number of CD4-, IL-2R- and ED-1-positive cells significantly increased in the glomeruli of rats with PAN nephrosis. However, in the present study, proteinuria was the earliest clinical manifestation in the course of PAN nephrosis. Therefore, it is likely that the accumulation of these cells in the glomeruli is secondary to PAN-induced alteration. There has been no evidence to suggest that PAN has a direct effect on mononuclear cells or it affects immunologic function. However, Schreiner et al. (21) noted that ultrastructural evidence of epithelial cell dysfunction is followed by an increase in the number of leukocytes in the glomeruli. Thus, it is controversial that leukocytes, including CD4-, IL-2R- and ED-1-positive cells, are involved in the development of PAN nephrosis.

On the other hand, recent studies have indicated that the abnormalities in lipid metabolism may be important in the pathogenesis of progressive renal injury in human and experimental glomerulonephropathy $(7,8)$. Clofibric acid, an antihyperlipidemic agent, ameliorated the degree of the renal injury in rats with reduced renal mass and the obese Zucker rat model of endogenous hyperlipidemia $(22,23)$. In addition, many reports $(9-11)$ demonstrated that renal injury is caused by a cholesterol-supplemented diet. These findings likely support the hypothesis that hyperlipidemia in the nephrotic syndrome may be as- sociated with progression of glomerular injury.

It is well-known that macrophages are important in the pathogenesis of atherosclerosis. It has been believed that atherosclerosis may be induced by which macrophages accumulate on the cholesterol-fixed endothelial cells in the vessel. On the other hand, the long term experiments on PAN nephrosis have documented that focal and segmental sclerosis in the glomeruli is observed by 90 days after PAN injection. Therefore, it is likely that macrophages may play a crucial role in the development of glomerular injury in PAN nephrosis as well as atherosclerosis. Kasiske et al. (22) reported that the cholesterol supplemented diet-fed rats had a greater amount of macrophages/monocytes and $\mathrm{T}$ lymphocytes in their glomeruli compared with those of standard diet-fed rats. Diamond et al. also demonstrated that peritoneal macrophages in PAN nephrosis exhibited enhanced phagocytic activity and thromboxane $\mathrm{A}_{2}$ release (14). Although those findings suggest the possibility that hyperlipidemia may be associated with progression of glomerular injury through the macrophage functions which are enhanced by PAN nephrosis, the present results indicated that mononuclear cell accumulation in the glomeruli occurred earlier than hyperlipidemia. Thus, the relationship between hyperlipidemia and mononuclear cells is obscure in PAN nephrosis.

In the additional experiments, we demonstrated that the administration of the subnephrogenic dose of PAN to cholesterol-supplemented rats substantially or significantly increased urinary protein excretion and CD4-, IL-2Rand ED-1-positive cells in the glomeruli, compared with those of standard diet-fed rats with subnephrogenic PAN 
nephrosis. While we feed the rats that were injected with the subnephrogenic dose of PAN with a $1 \%$ cholesterol diet in the present study, many investigators used a $4 \%$ cholesterol diet in their experiments. We used the $1 \%$ cholesterol diet to avoid the glomerular alteration by hyperlipidemia itself as described above. Therefore, this result suggests that hyperlipidemia expands unsusceptible renal lesions by activated mononuclear cells. Moreover, cholestyramine and simfibrate ameliorated the urinary protein excretion and the increase in the number of CD4-, IL-2R- and ED-1-positive cells. In the present experiments, we used $1,000 \mathrm{mg} / \mathrm{kg}$ of cholestyramine and simfibrate. This dose is likely considered to be an overdose pharmacologically. Rabelink et al. (24) failed to reduce the cholesterol level in the nephrotic syndrome caused by the administration of $16 \mathrm{~g} /$ day of the cholestyramine for 6 weeks. Kasiske et al. (23) demonstrated that $200 \mathrm{mg} / \mathrm{kg}$ clofibrate was not enough to reduce the cholesterol level in obese Zucker rats that spontaneously develop hyperlipidemia and albuminemia. Additionally, in the preliminary experiment, we did not observe any effect to reduce the cholesterol level using $750 \mathrm{mg} / \mathrm{kg}$ of these drugs in PAN nephrosis rats for 2 weeks (data not shown). Therefore, we administered such a higher dose of each antihyperlipidemic agent to produce a lower level of the cholesterol in a short period. PAN nephritic rats did not appear to suffer from adverse effects throughout the experimental period.

Treatment with azathioprine and cyclosporin A improved the urinary protein excretion and increases in the numbers of CD4-, IL-2R- and ED-1-positive cells. Azathioprine and cyclosporin $\mathrm{A}$ also inhibited the increases in plasma cholesterol and creatinine contents in PAN nephrosis (data not shown). However, the inhibitory effects of immunosuppressive agents on urinary protein excretion and increase in mononuclear cell number were less than those of antilipidemic agents. These results suggest the mechanisms by which $\mathrm{T}$ lymphocytes and macrophages were activated by hyperlipidemia may be antigen-non-specific rather than antigen-specific.

The depleting leukocyte study with monoclonal antibodies demonstrated that increases in the numbers of CD4-, IL-2R- and ED-1-positive cells substantially are associated with the progression of PAN nephrosis. Monoclonal antibodies against the three surface antigens prevented urinary protein excretion. However, W3/25 monoclonal antibody (against CD4) had not prevented the urinary protein excretion by the 11th day. These results suggest that the increase in the number of activated helper $T$ cells bearing IL-2R and macrophages in the glomeruli may play more important role in the progression of PAN nephrosis than the increase in nonactivated helper $\mathrm{T}$ cells.
In conclusion, we propose that the activation of these cells is caused by hyperlipidemia in the nephrotic syndrome and the accumulation of these cells in the glomeruli is associated with the progression of glomerular injury. However, further investigation is required to elucidate where macrophages and $\mathrm{T}$ lymphocytes could be activated in PAN nephrosis rats; namely, it is unclear whether these cells are activated in the circulation or in the glomeruli.

\section{REFERENCES}

1 Ryan GB and Karnovsky MJ: An ultrastructural study of the mechanisms of proteinuria in aminonucleoside nephrosis. Kidney Int 8, 219-232 (1975)

2 Thakur V, Walker PD and Shah SV: Evidence suggesting a role for hydroxy radical in puromycin aminonucleoside-induced proteinuria. Kidney Int 34, 494-499 (1988)

3 Diamond JR, Bonventre JV and Karnovsky MJ: A role for oxygen free radicals in aminonucleoside nephrosis. Kidney Int 29, 478-483 (1986)

4 Harris KPG, Lefkowith JB, Klahr S and Schreiner GF: Essential fatty acid deficiency ameliorates acute renal dysfunction in the rat after the administration of the aminonucleoside of puromycin. J Clin Invest 86, 1115-1123 (1990)

5 Kasiske BL, O'Donnell MP, Schmitz PG, Kim Y and Keane WF: Renal injury of diet-induced hypercholesterolemia in rats. Kidney Int 37, 880-891 (1990)

6 Koyama A, Fujisaki M, Kobayashi M, Igarashi M and Narita M: A glomerular permeability factor produced by human $T$ cell hybridomas. Kidney Int 40, 453-460 (1991)

7 Gheradi F, Rota E, Calandra S, Genova R and Tamborino A: Relationship among the concentrations of serum lipoprotein and changes in their chemical composition in patient with untreated nephrotic syndrome. Eur J Clin Invest 7, 563-570 (1977)

8 Moorhead JF: Lipids and progressive kidney disease. Kidney Int 39, S35-S40 (1991)

9 Keane WF, Mulcahy WS, Kasiske BL, Kim Y and O'Donnell MP: Hyperlipidemia and progressive renal disease. Kidney Int 39, S41-S48 (1991)

10 Preic-Golia L and Peric-Golia M: Aortic and renal lesions in hypercholesterolemic adult, male virgin Sprague-Dawley rats. Atherosclerosis 46, 57-65 (1983)

11 Wellmann KF and Volk BW: Renal lesions in experimental hypercholesterolemia in normal and in subdiabetic rabbits II. Long term studies. Lab Invest 24, 144-155 (1971)

12 French SW, Yamanaka $W$ and Ostwald R: Dietary induced glomerulosclerosis in the guinea pig. Arch Pathol Lab Med 83, 204-210 (1967)

13 Rogners KA, Hoover RL, Castellot JJ, Robinson JM and Karnovsky MJ: Dietary cholesterol-induced changes in macrophage characteristics. Am J Pathol 125, 284-291 (1986)

14 Diamond JR, Pesek I, McCarter MD and Karnovsky MJ: Altered functional characteristics of rat macrophages during nephrosis. Synergistic effects of hypercholesterolemia. Am J Pathol 135, 711-718 (1989)

15 Kingsbury FB, Clark CP, Williams $G$ and Post AL: The rapid determination of albumin in urine. J Lab Clin Med 11, 981 - 989 
(1926)

16 Hancock WW, Becker GJ and Atkins RC: A comparison of fixatives and immunohistochemical technic for use with monoclonal antibodies to cell surface antigens. Am J Clin Pathol 78, 825-831 (1982)

17 Arima S, Nakayama $M$, Naito $M$, Sato $T$ and Takahari $K$ : Significance of mononuclear phagocyte in IgA nephropathy. Kidney Int 39, 684-692 (1990)

18 Hattori T, Nagamatsu T, Ito $M$ and Suzuki $Y$ : Contribution of ED-1 and CD8 antigen positive cells in glomeruli during the course of anti-GBM nephritis. Jpn J Nephrol 36, 20-31 (1994)

19 Shaloub RJ: Pathogenesis of lipoid nephrosis: A disorder of T cell function. Lancet 2, 556-560 (1974)

20 Eyres K, Mallick NP and Taylor G: Evidence for cell-mediated immunity to renal antigens in minimal change nephrotic syndrome. Lancet 1, 1158-1159 (1976)
21 Schreiner GF, Cotran RS and Unanue ER: Modulation of Ia and leukocyte common antigen expression in rats glomeruli during the course of glomerulonephritis and aminonucleoside nephrosis. Lab Invest 51, 524-533 (1984)

22 Kasiske BL, O'Donnell MP, Garvis WJ and Keane WF: Pharmacologic treatment of hyperlipidemia reduces glomerular injury in rat $5 / 6$ nephrectomy model of chronic renal failure. Circ Res 62, 367-378 (1988)

23 Kasiske BL, O'Donnell MP, Cleary MP and Keane WF: Treatment of hyperlipidemia reduces glomerular injury in obese Zucker rats. Kidney Int 33, 667-672 (1988)

24 Rabelink AJ, Hene RJ, Erkelens DW, Joles JA and Koomans HA: Effects of simvastatin and cholestyramine on lipoprotein profile in hyperlipidemia of nephrotic syndrome. Lancet $\mathbf{1}$, $1335-1338$ (1988) 